\title{
冰上丝绸之路海洋科技创新战略研究
}

\author{
李大海 $^{1}$, 张荧楠 $^{2}$ \\ (1. 中国海洋大学海洋发展研究院, 山东青岛 266100；2. 中国海洋大学管理学院，山东青岛 266100）
}

\begin{abstract}
摘要：“冰上丝绸之路” 共建是我国参与北极保护、开发与治理的重要途径。科技创新是我国推进 “冰上丝绸之路” 共建的 重要支撑。我国在北极科学考察、科研基础设施建设、装备研发制造等方面已经具有一定的基础, 但也存在统筹机制弱、投 入不足、平台建设滞后等问题。应围绕《中国的北极政策》白皮书和 “冰上丝绸之路” 共建的有关原则, 大力推进北极海洋 认知、保护、开发和治理相关科学技术创新和人文社科研究, 在北极海洋观测、海洋海冰研究、生物和生态系统研究、污染 防治、气候变化响应、航运技术、油气开发技术等方面谋求取得更大突破。通过加强双边多边合作、发起国际大科学计划、 建立公共平台、加强人才交流与培养等方式，推动 “冰上丝绸之路”科技创新不断走向深入。
\end{abstract}

关键词: “冰上丝绸之路”; 海洋科技; “一带一路”

中图分类号：F110 文献标识码：A

\section{Marine Science and Technology Innovation for the Polar Silk Road}

\author{
Li Dahai ${ }^{1}$, Zhang Yingnan ${ }^{2}$ \\ (1. Marine Development Studies Institute of Ocean University of China, Qingdao 266100, Shandong, China; \\ 2. Management College of Ocean University of China, Qingdao 266100, Shandong, China)
}

\begin{abstract}
The co-construction of the "Polar Silk Road" is an important way for China to participate in the protection, exploitation, and governance of the Arctic, and scientific and technological innovation is an important support for promoting the co-construction. China has a certain foundation in scientific expedition, scientific research infrastructure construction, equipment research and manufacturing for the Arctic. However, there still exist some problems such as a weak overall planning mechanism, inadequate investment, lagging in platform construction. Based on the white paper titled China's Arctic Policy and the relevant principles for the "Polar Silk Road", China should vigorously promote scientific innovation and humanistic research related to the knowledge, protection, exploitation, and management of oceans in the Arctic; and make larger breakthroughs in marine observation, sea ice research, biological and ecological systems, pollution control, response to climate change, shipping technology, and oil and gas development technology. To promote the scientific and technological innovation for the "Polar Silk Road", China should strengthen bilateral and multilateral cooperation, launch international scientific programs, establish public platforms, and strengthen talent exchange and training.
\end{abstract}

Keywords: Polar Silk Road; marine science and technology; ocean; the Belt and Road

收稿日期 : 2019-06-10; 修回日期 : 2019-09-25

通讯作者: 李大海, 中国海洋大学海洋发展研究院研究员、博士后, 主要研究方向为海洋经济与科技管理; E-mail: sunrain1932@163.com 资助项目：中国工程院咨询项目 “海洋强国战略研究 2035” (2018-ZD-08); 山东省社科规划项目 “山东省建设海洋综合性国家科学中心研 究” (19CHYJ09)

本刊网址 : www.engineering.org.cn/ch/journal/sscae 


\section{一、前言}

“冰上丝绸之路” 是指穿越北极圈, 连接北 美、东亚和西欧三大经济中心的海运航道。2017 年 7 月 3 日, 中国国家主席习近平与俄罗斯总统普京 提出要开展北极航道合作, 共同打造 “冰上丝绸之 路”。2018 年 1 月 26 日，我国政府发表首份北极政 策文件一 《中国的北极政策》白皮书，提出中国 愿依托北极航道的开发利用，与各方共建 “冰上丝 绸之路”。“冰上丝绸之路” 包括 “东北航道” 和 “西 北航道”。其中，中俄共建的是 “东北航道”。“冰 上丝绸之路” 贯穿北冰洋, 几乎覆盖全部北极海域 和海岸带。“冰上丝绸之路” 沿线海域是人类长期 以来少有涉足的区域。人类对北极认知还很有限, 应对北极海洋恶劣自然条件的能力仍比较薄弱。依 托 “冰上丝绸之路” 共建, 积极开展北极海洋相关 科学研究和技术开发合作, 不仅是 “冰上丝绸之路” 共建的重要内容，也是我国积极参与北极认知、北 极开发、北极保护和北极治理的重要手段。

\section{二、战略需求}

\section{（一）增强海上航运安全保障}

我国货物贸易中有 $90 \%$ 以上通过海路运输, 海 上航线堪称我国经济的 “生命线”。“冰上丝绸之路” 建设为我国优化海上航运格局、增强航运安全保障 能力，提供了一条新道路。“冰上丝绸之路”与我 国传统的海上贸易航线形成了良好补充, 能够大幅 减小我国与欧洲（特别是北欧）国家的航程 $[1,2]$, 可以极大地降低燃料费和航行时间 [3]。但是, “冰 上丝绸之路” 海域常年被冰层和浮冰所覆盖, 且在 夏秋季节容易在开放海域形成高度变化和不可预测 的冰流，这对造船技术、船用装备制造技术、导航 技术和气象水文冰情预报技术均提出了很高要求。 为了更好地发挥 “冰上丝绸之路” 的航运功能、降 低航运风险, 迫切需要推动开展相关技术创新。

\section{（二）优化油气供给空间结构}

我国是石油进口依赖度极高的国家，2017 年石 油进口依赖度为 $72.3 \%$ 。北极蕴藏的丰富的海洋油 气资源 [4], 有可能成为重要的油气开采区, 成为 我国新的重要油气供给来源地 [5]。但是, 北极海
底地貌特征复杂、海陆通行条件很差、生态环境脆 弱, 一旦出现溢油等事故后很难得到及时处置, 有 可能引起严重的生态灾难 [6]。所以, 需要开发适 用于北极海域的油气勘探、开采和环境保护技术, 降低开发成本，增大开发安全性。

\section{（三）发展北极海洋新兴产业}

除了航运和油气外, 北极海洋捕捞和海洋旅游 也有望发展成为重要的海洋新兴产业。海冰融化使 商业捕捞的边界向北推移 [7], 也提升了北极海上 旅游的经济可行性, 有望形成新的海洋新兴产业。 但是, 北极海洋渔业资源分布及其随气候变化而改 变的幅度尚未得到充分评估，也缺少具有一定破冰 能力和较强续航、通信和安全保障能力, 又能够较 好满足捕捞作业和观光旅游需求的极地渔船和极地 邮轮, 以及配套船用装备。所以, 加强相关领域的 科技创新, 是发展北极海洋新兴产业的前提和支撑。

\section{（四）更好参与北极治理}

北极变化正在深刻影响着全球地缘政治格局, 地缘经济的变化必然引起地缘政治格局的改变。人 类对北极地区的了解还很不充分, 对北极的进入、 认知和开发能力还相当有限。面对北极地区复杂多 变的气象水文冰情, 北极开发与保护的所有活动, 都离不开海洋科学技术的支撑。积极参与北极科技 创新活动, 并争取在北极认知、北极航行、环境保 护、资源开发等技术创新领域发挥重要作用, 成为 我国参与北极治理的重要手段。

\section{三、现状基础}

\section{（一）发展现状}

自从 1999 年我国开始北极科考以来，我国的 北极海洋科技创新活动进入了持续发展的新阶段。 经过 20 年的发展, 在北极海洋科学考察、装备能 力建设、科学研究成果、技术研发突破和合作载体 建设方面, 都取得了长足发展。这为 “冰上丝绸之 路” 海洋科技合作创新活动奠定了良好基础。

一是北极科学考察常态化。我国于 1996 年成 为国际北极科学委员会成员国, 1999 年起以 “雪龙” 号科考船为平台, 开展了 9 次北冰洋科学考察。科 考船到达了北极绝大部分海域并进行观测, 通过对 
东北航道、西北航道有关水文冰情的观测, 我们对 北极冰情、水文、地质、生物资源等情况有了初步 了解。锻炼形成了北极科学家团队、技术服务团队 和航行保障团队, 全面形成了北极观测和科学研究 能力。

二是基础设施建设不断推进。我国在北极地区 的科研基础设施主要包括科考船、基地、观测台站。 经过 20 多年的发展, 我国已经形成了“两船、两站” 的北极科考基础设施格局。“两船” 系 “雪龙” 号和 “雪龙 2 ” 号极地考察船。其中, “雪龙” 号先后执 行了 22 次南极考察和 9 次北极考察。“两站”系北 极黄河站和中国 - 冰岛北极科学考察站。北极黄河 站建成于 2004 年, 位于挪威斯匹茨卑尔根群岛的 新奥尔松地区。中国 - 冰岛北极科学考察站建成于 2018 年, 位于冰岛北部凯尔赫村, 是由中冰联合极 光观测台升级而成。

三是北极科学研究水平稳步提高。建立了覆盖 海冰快速消退期浮游动物群落的完整数据库和北极 科考海冰漂流自动气象观测站, 发现北大西洋和南 大洋的深层热汇作用增强是 21 世纪初全球变暖减 缓的重要原因, 最近 20 年来全球海平面加速上升 的主要原因是格陵兰冰盖融化加剧。在水团与环流 变化、陆架 - 海盆水交换、冰架下海洋过程、温室 气体收支、海洋酸化、生物地球化学、海洋生物多 样性与生态系统演化、冰 - 海耦合模式与数据同化 等方面取得重要成果。

四是极地技术创新取得新突破。围绕极地战略 新疆域的研究不断深入开展, 研发了一批重大技术 和装备, 为我国极地考察提供现场保障和支撑能力, 填补了我国在极地科考重大装备领域的多项空白, 展示了中国装备和中国制造的实力。建造了全球首 艘双向破冰技术的极地科考破冰船（“雪龙 2 ” 号)、 全球首艘极地重载甲板运输船、全球首艘极地冷凝 析油轮、我国首座适合北极海域作业的深水半潜式 钻井平台 (“维京龙”号)。

\section{（二）存在问题}

在肯定取得成绩的同时, 也要看到差距和不足。 我国极地科技发展水平距离极地强国仍存在较大差 距, 极地研究以跟踪为主, 缺乏原始创新。我国极 地科技发展整体水平还不能适应国民经济和社会发 展的需要, 极地科技自主创新和成果转化能力还不
能满足增强极地能力拓展的战略需求。

一是北极海洋基础研究与极地科技强国差距较 大。文献计量学分析表明, 我国与以美国为代表的 北极海洋科技强国仍有较大差距。我国的 SCI 论文 数量不仅与美国差距较大, 也全面落后于加拿大、 日本、德国和北欧五国。

二是北极海洋科技投入不足。我国尚未建立系 统化的极地科研资助渠道。对北极科研项目的资助 分散在各个相关部门设立的项目之中。项目资助的 系统性、延续性均不强。国家自然科学基金委员会 一直是相关科研的主要资助方 (1995 年起)。“南北 极环境综合考察与评估” 专项主要针对业务化考察 与评估 (2011 年起)。2016 年以来, 国家重点研发 计划对北极研究资助力度明显加大。但由于基础设 施薄弱、历史欠账较多等原因, 目前我国对北极相 关科技创新的投入仍显不足。

三是国家北极科技创新统筹机制薄弱。受我国 科技管理部门化和科技资源 “碎片化” 的影响, 我 国始终未能凝聚共识形成国家北极科技战略。北极 相关科学研究主要由自然资源部极地考察办公室来 统筹推动, 难以形成对隶属于全国各部委、各系统 的各类科研机构极地研究的统筹。由于北极相关科 学研究 “大综合” 的特点, 各系统、各学科之间在 项目设立、基础设施利用、经费分配等方面也存 在一定的非系统化特性, 难以形成合力。在国家 北极政策指导下, 最大限度地整合国内相关科技 力量, 形成整体合力, 是我国迫切需要研究解决 的重要问题。

综上, 北极基础研究能力、科技投入、国家战 略、统筹机制等方面的问题, 对依托冰上丝绸之路 共建开展海洋科技合作带来了诸多不利影响。随着 冰上丝绸之路建设不断向纵深推进, 上述问题有可 能进一步凸显。有必要认真分析问题的产生原因, 有针对性地加以解决。

\section{四、总体构想}

\section{（一）指导思想}

以习近平新时代中国特色社会主义思想为统 领, 全面贯彻落实党的 “十九大” 精神, 遵循 “一 带一路” 倡议的基本理念和原则, 围绕《中国的 北极政策》白皮书关于认识北极、保护北极、利用 
北极和参与北极治理四大主题, 依托冰上丝绸之 路沿线重要支点国家, 大力推进北极海洋观测（探 测）和基础研究、海洋生态环境保护技术开发、北 极海洋开发工程技术开发和北极涉海人文社科研究 合作, 积极参与和珲头筹建北极海洋相关国际科学 组织, 找准定位发挥大国作用, 结合北极国家与主 要北极科技强国各自科技发展需求及与我国的互补 性, 通过加强政府间合作、共建科研平台、共同发 起推进北极大科学计划、共同举办学术论坛、强化 人员交流与培训等方式, 促进我国冰上丝绸之路海 洋科技创新能力与水平的全面提升, 使我国在北极 海洋认知、保护、开发与治理中发挥更大作用。

\section{（二）主要原则}

将认识北极海洋作为 “冰上丝绸之路” 海洋科 技创新的核心任务。我国北极科考起步较晚, 北极 科研基础比较薄弱, 技术水平不高, 认知不足已经 成为我国参与北极海洋事务的最大短板。应当加大 投入, 围绕北极海洋水文、冰情、气象、地质、北 极与全球变化等基础科学问题, 开展深入研究, 尽 快使我国北极海洋认知能力跨入国际先进行列。

将保护北极海洋作为 “冰上丝绸之路” 海洋 科技创新的根本遵循。保护北极海洋独特的自然 环境和生态系统, 尊重多样化的社会文化和历史 传统, 应当成为我国践行海洋命运共同体理念的重 要行动。唯有如此, 我国推动 “冰上丝绸之路” 海 洋科技创新的理念与行动才能得到北极国家的认可 和支持。

将开发北极海洋作为 “冰上丝绸之路” 海洋科 技合作的长期目标。北极航运、油气开发等经济活 动具有巨大的经济开发潜力, 也面临巨大的自然风 险、市场风险和社会风险。应当遵循可持续发展目 标, 将北极海洋开发的重点放到环境友好型技术模 式和商业模式探索方面。

将参与北极治理作为 “冰上丝绸之路” 海洋科 技合作的重要实践。一方面, 认真履行北极理事会 观察员职责, 在现有国际法框架内发挥积极作用; 另一方面, 在北极航运、污染防治、渔业资源开发 与保护、应急救援等方面的规则制定中发挥大国作 用, 推动相关机制、平台建设, 扮演好相关公共服 务重要提供者角色, 在北极治理深化过程中发挥关 键作用。

\section{（三）发展目标}

依托 “冰上丝绸之路” 共建, 推动我国与北极 国家建立长期稳定科技合作关系, 逐步强化与国际 主要北极科技强国的交流与合作。解决我国观测能 力不足、观测支点薄弱的瓶颈问题，基本建立 “冰 上丝绸之路” 海洋观测体系, 推动北极海洋研究、 海冰研究的全面展开, 实现海 - 冰 - 气综合观测和 高精度模式构建, 提高气象水文预测预报的准确性。 基于综合观测系统的北极海洋生物多样性与生态系 统演化研究取得重大进展, 对北极海洋酸化、微塑 料污染等重大环境问题的认知水平大幅提升, 开发 适用的海洋环境污染评估和治理技术。基本摸清北 极与全球气候变化的关联及全球变化对北极的影 响, 并将之纳入北极海洋治理的总体考量。基本摸 清北极海洋航道资源、油气资源、渔业资源、金属 矿产资源等重要资源的分布和储量, 与北极开发相 关的装备制造技术、造船技术、油气勘探开采技 术、渔业探捕技术达到产业化开发要求, 北极海 洋通用技术达到世界领先水平。北极涉海人文社 科研究全面展开, 取得丰硕成果, 在我国参与北 极治理中发挥重要作用。

\section{五、重点任务}

\section{（一）以更好认识北极为目标, 开展 “冰上丝绸之 路” 海洋观测和基础研究}

开展北极海洋学研究。加强我国北极考察站、 船、飞机等基础条件平台建设, 增强北极数据获取 能力。强化与北极国家的合作, 推进海 (冰)、陆 基和空基的北极观测网建设, 实现基础环境参数的 长期无人值守自动观测。重点发展北极太平洋扇区 观测组网技术, 支持太平洋入流水及其对北冰洋环 境和生态系统影响的研究和预测。强化北冰洋中央 区生态探测手段, 支持北冰洋中央区生态变化评估 和预测。

开展北极海冰研究。加强与俄罗斯、德国等北 极科研机构的合作, 建设空、天、水面和水下一体 的观测网络。以北冰洋中央区为重点, 开展对大气海冰 - 海洋的一体化观测, 了解大气 - 海冰 - 海洋 间相互作用的影响。重点开展浮冰观测和过程研究, 参与国际北极浮标计划, 搜集海冰数据, 研究影响 海冰覆盖动力学和热力学的北冰洋过程、相互作用 
和反馈。

增强北极卫星协同观测能力。大力发展卫星 遥感和数据处理技术, 研发和形成一系列有自主知 识产权、有国际影响力的极地关键要素遥感产品。 提高我国北极观测的天基数据获取能力, 将之作 为我国与北极国家及近北极国家合作的重要技术 支撑。构建 “天空地”一体化观测系统。强化对 北极海冰、北冰洋初级生产力和格陵兰冰盖的观 测和基础科学研究。

\section{（二）以更好保护北极为目标, 开展 “冰上丝绸之 路”海洋生态环境保护和气候变化应对研究}

开展北极海洋生物多样性与生态系统演化研 究。加强国际合作, 建设海洋生态系统研究平台与 观测网络, 对生物生态及生物多样性进行多层次和 多领域的连续观测。分析北极特殊生存环境下的生 物多样性、独特生命特征及适应与进化机制, 认识 气候变化和人类活动对北极海洋脆弱生态系统的影 响, 揭示北冰洋生态系统和生物地化过程对海冰消 退的影响。

开展典型北极生物研究。加强对北极海洋生物 物种分布和规模情况的认识。加强典型生物栖息地 监测, 了解北极熊、海豹、代表性海鸟的分布和数 量情况。评估北极物种的摄食生态, 填补季节性数 据空白, 确定食物链中关键链接的基本生活史信息、 年龄和增长率。加强对典型北极生物及其栖息地的 保护, 推动建立北极海洋自然保护区。

开展北极海洋环境污染评估和治理技术开发。 通过联合设立国际科学计划、共建科学考察站和海 洋观测站等方式, 加强北极海洋环境背景调查, 建 立海洋环境数据库, 发展环境多介质污染物监测、 新兴污染物笁查等技术方法, 开展极区典型污染物 (包括持久性有机污染物、永、微塑料、放射性物 质等) 的观测。研究典型污染物在北极大气和海洋 中的时空分布和迁移转化特征; 研究全球变化对北 极海洋污染物再释放的影响, 污染物在北极海洋生 态系统中的积累及其毒理效应。研究北极碳氮循环 对全球气候变化的响应与反馈, 特别是北极海洋碳 储库变动对海洋酸化的影响, 及其生物地球化学机 制。评估航运、油气开发、捕捞渔业等人类活动 对北极海洋环境的影响, 研发北极海洋污染物去 除技术。
开展全球气候变化对北极海洋的影响研究。用 各国对北极大气、冻土、冰川的观测数据, 结合海 洋、海冰观测数据, 开展全球气候变化的北极海洋 影响研究。研究极地海冰、水团与环流变化, 明确 其与全球翻转环流变化和气候增暖的关系。全面认 识北极陆 - 海 - 冰 - 气的能量和物质交换过程, 发 展北极区域耦合数值模式, 提高气象预报精确度。 研究极地冰盖、冰川动力过程对海平面的影响。分 析全球气候变化对北极海洋及其生态变化过程的影 响, 预测全球变暖背景下北极海洋生态环境和生物 多样性趋势。

\section{（三）以更好利用北极海洋为目标, 开展 “冰上丝 绸之路”海洋工程技术研发}

开发北极观测（探测）装备制造技术。围绕北 极观测网建设和北极油气、渔业资源勘探对相关装 备的需求, 加快开发高纬度海域适用观测 (探测) 技术装备。根据北极气象水文特点, 研制开发具有 自主知识产权的极地海域专用温湿压、风浪流、温 盐密声、海冰等极区环境参数测量仪器设备, 并根 据观测需求逐步开发谱系化装备。研制开发高纬度 海域适用的长航程、抗恶劣环境、自动化观测运载 装备, 打造满足科学研究和资源开发要求的观测 ( 探 测）平台。以极地卫星为核心，研制开发极地观测 通信技术, 开发极地观测组网技术。

开发北极高性能船舶技术。围绕服务 “冰上丝 绸之路” 建设, 针对北极多浮冰、低温、多雾、多 风暴等特点, 以保障船体结构安全、船舶稳定性、 机舱设备正常运行、船上人员与货物安全等方面为 重点, 加大技术研发力度, 提升极区船舶建造技术 水平。针对低温会降低钢材的承载性问题, 优化船 体结构设计, 开发极区船舶专用特种钢材冶炼技术, 提升极地船舶运动性能和结构特性。针对低温下船 舶重要部位易结冰等问题, 进行结构优化和专用加 热除冰设备开发。推动 “智慧航运” 技术在 “冰上 丝绸之路” 船舶航行中的应用, 研发具有自主知识 产权的极地航行安全智能决策辅助系统。

开发北极资源勘探与利用技术。在油气勘探环 节, 针对北极海底凹凸不平和非均质性特征, 开发 可控源电磁探测法 (CSEM) 等高纬度深海油气勘 探技术。在油气钻采环节, 加快开发适合在极区海 域恶劣环境中钻井作业的钻井船和钻井平台技术, 
包括耐低温材料、加热系统、抗厚冰层和风暴海浪 冲击结构和针泊技术等。在油气运输环节, 加快开 发具有破冰能力的液化天然气（LNG）船建造技术 和高纬度海域水下油气管道设计铺设技术。开发极 区海域海洋平台事故的应急处理技术，研究溢油等 紧急事故预警、应急和决策系统, 研制极区海域平 台应急救助装备。加快设计建造具有较强破冰能力 和续航能力的北极海域渔业资源调查船, 开展北极 主要渔业资源调查。

开发北极海洋通用技术。重点发展极地导航、 通信、低温材料等通用技术。研究开发适用于极地 严寒、抗磁暴的高可靠性通信技术，开发极地卫星 通信系统。研究开发极地导航装备, 联合 “冰上丝 绸之路” 沿线国家制定统一极区导航标准, 研发适 用于高纬度地区的惯性罗经和惯性导航设备。开展 极地声学参数获取与应用、极地冰层波导及冰下声 学特性、极地声学反演等方面的研究, 开发冰层覆 盖下通信、探测、定位和导航技术。研究开发极地 适用的低温钢、低温涂层技术, 研发耐低温、耐磨、 耐腐蚀、易焊接的极地适用新材料。研究开发极地 工程建筑设计建造技术，开发成套技术装备。

\section{（四）以更好参与北极海洋治理为目标, 开展 “冰} 上丝绸之路”人文社科研究

加强北极国别研究。系统研究国际北极竞争与 合作形势, 描述北极国家及主要近北极国家的地缘 特征、北极开发历史、北极主张、北极竞争与合作 行为, 分析隐藏在国家行为之后的利益诉求和博亦 态势。针对有关国家在北极重大问题上存在分歧, 结合我国推进 “冰上丝绸之路” 建设的总体目标, 研究形成差别化的合作策略。篮选能够凝聚最大共 识的国际话题, 提出能够获得广泛支持的主张和国 际科学计划, 逐步扩大我国在北极治理中的话语权。

开展北极航线开发相关社科研究。基于船舶北 极航行国际法, 加强我国对北极航运新规则及对策 研究。基于国别研究成果, 对 “冰上丝绸之路” 沿 线国家、特别是俄罗斯（东北航线）和加拿大（西 北航线) 的北极航道法律法规和管理规制进行研究, 分析其航线管理的典型案例。基于双方利益契合点, 探讨与沿线国家在航线利用、基础设施共建、航运 安全管理和应急救援方面的合作机制, 探讨共同建 设 “冰上丝绸之路” 的 “智慧航运” 体系，共建航
运信息监测系统、大数据管理中心和航运服务支持 体系的可行性。共同开展 “冰上丝绸之路” 航运开 发环境风险分析和环境管理机制研究, 实现北极航 线的可持续开发。

开展北极资源开发相关社科研究。研究国际油 气供需长期趋势，分析预测北极油气开发对国际原 油市场的影响, 以及对全球经济发展的影响。研究 分析北极油气开发对全球气候变化、海洋可持续发 展和新能源技术进步的影响。研究北冰洋渔业相关 国际规则, 分析北冰洋渔业国际管理制度形成过程 中各利益相关方的竞争与合作态势, 研究气候变化对 北冰洋渔业资源可持续利用的影响, 明确我国开发 与保护北冰洋渔业资源的主张。研究 “冰上丝绸之 路” 沿线国家的渔业管理法律规制, 通过设立联合 渔业资源调查项目、共建渔业资源保护平台、共同 研发绿色捕捞技术等方式, 积极为我国争取入渔权。

\section{六、推进措施}

围绕 “冰上丝绸之路” 共建, 以提升我国北极 海洋科技创新能力为目标, 以强化双边、多边合作 为主线, 以共建科研基础设施、共同发起国际科学 计划、共同打造数据共享平台、共同打造北极科学 论坛为主要手段, 以构建新型科技合作机制为内在 动力, 推进 “冰上丝绸之路” 海洋科技合作。

\section{（一）推动国际双边极地科技合作}

依托 “冰上丝绸之路”建设, 加强与俄罗斯、 北欧五国的北极科学研究合作, 通过签署共建备忘 录、联合建设科研机构 (平台)、共同实施科学研 究项目等方式, 进一步展开我国北极科学布局。联 合德国、法国、英国、加拿大等国家具有较强实力 的北极研究机构, 共建一批国际联合实验室和联合 研究中心, 作为承担政府间北极科技合作和双边国 际合作项目的载体。

\section{（二）利用多边极地科技合作与交流平台}

积极参与北极理事会、北极科学部长级会议、 北极圈论坛和北极前沿论坛等国际极地议事平台。 依托 “冰上丝绸之路” 建设, 积极推动亚洲极地 科学论坛、中国 - 北欧北极研究中心和金砖国家 极地与海洋合作框架等多边国际合作平台建设, 
建立北极研究合作网络体系。加强（近）北极国 家之间的交流与合作，推动构建北极科研基础设 施和数据信息共享机制, 促进各国北极科学研究 水平的共同提高。

\section{（三）丰富海洋科技合作层次}

在积极谋求建立政府间合作的同时，建立多层 次海洋科技合作模式。一是发挥各大学和科研单位 的作用, 采取建立单位合作伙伴关系、联合承担科 研项目、共建科研团队、人才引进与交流等方式, 夯实 “冰上丝绸之路” 海洋科技合作的基础; 二是 发挥科学技术部、中国科学院、农业农村部等部门 的作用, 积极与 “冰上丝绸之路” 沿线国家在行业、 领域建立合作关系; 三是发挥中国海洋石油集团有 限公司、中国船舶重工集团公司等企业的作用, 通 过并购国外科技企业、承建国外工程、合作实施海 洋开发、购买国外技术、招聘国外研发团队等方式, 增进与沿线国家的产业技术合作; 四是发挥地方政 府作用, 通过建立友好城市关系、举办国际科技论 坛等方式, 为 “冰上丝绸之路” 海洋科技合作营造 良好氛围。

\section{（四）牵头发起北极海洋国际大科学计划}

发挥我国 “后发优势”, 牵头发起我国主导的 北极国际大科学计划。一是以我国在青藏高原的研 究优势为基础, 牵头发起 “三极” 国际大科学计划, 重点研究北极、南极和青藏高原对全球变化的响应 与作用; 二是发挥 “一带一路” 共建形成的平台优 势, 依托热带国家与北极国家在海洋研究方面的各 自优势, 牵头发起 “极地一热带海洋” 联合观测, 探索高纬度海洋与低纬度海洋之间的联系与相互 作用; 三是以资源开发和航运保障为重点, 牵头 发起 “透明冰上丝绸之路” 计划, 实现对 “冰上 丝绸之路” 沿线海域的全面认知。

\section{（五）构建北极海洋大数据平台}

依托北极国际大科学计划开展, 逐步建立统一 的海洋数据观测和传输标准。牵头建设面向全球开 放的北极海洋数据中心, 利用我国海洋超级计算平 台, 开展极地科学数据的空间数据挖掘技术、时间 序列分析技术、多学科数据关联分析技术、高维数
据处理技术、可视化分析技术等的研究和应用。集 成和融合北极多学科数据, 与全球观测数据进行整 合, 依托大数据技术开发全球气候变化和气象海洋 灾害监测预报系统。

\section{（六）加强人才交流与培养}

以科研人员和工程技术人员为重点, 利用访问 学者、博士后交流, 学位教育、短期交流等形式, 大力推动科技人才 “走出去”, 学习先进国家北极 研究方法和技能。通过举办国际学术会议、讲学座 谈、联合组建研究团队等形式, 加大对北极研究强 国优秀科研人员的交流，搭建思想碰撞与技能学习 的平台。针对 “一带一路” 沿线非北极国家的北极 海洋科学研究需求, 利用留学、吸纳进入课题组等 方式, 加强对沿线非北极国家相关海洋科研人员的 培养, 增强合作国北极科研能力, 增进双方合作开 展海洋研究的积极性。

\section{参考文献}

[1] Schøyen H, Bråthen S. The Northern Sea Route versus the Suez Canal: Cases from bulk shipping [J]. Journal of Transport Geography, 2011, 19(4): 977-983.

[2] Lasserre F. Case studies of shipping along Arctic routes. Analysis and profitability perspectives for the container sector [J]. Transportation Research Part A Policy \& Practice, 2014, 66(1): 144-161.

[3] 张侠, 屠景芳, 郭培清, 等. 北极航线的海运经济潜力评估及其 对我国经济发展的战略意义 [J]. 中国软科学, 2009 (S2): 86-93.

Zhang X, Tu J F, Guo P Q, et al. Assessment of the economic potential of Arctic shipping and its strategic significance to China's economic development [J]. China Soft Science, 2009 (S2): 86-93.

[4] Gautier D L, Bird K J, Charpentier R R, et al. Assessment of undiscovered oil and gas in the Arctic [J]. Science, 2009, 324(5931): 1175-1179.

[5] 肖洋. 中俄共建 “北极能源走廊”: 战略支点与推进理路 [J]. 东 北亚论坛, 2016, 25(5): 109-117, 128.

Xiao Y. China-Russia joint construction of "Arctic Energy Corridor": Strategic fulcrum and promoting way [J]. Northeast Asia Forum, 2016, 25(5): 109-117, 128.

[6] 杨振姣, 崔俊, 韩硕洋, 等. 北极生态安全对中国国家安全的影 响及应对策略 [J]. 海洋环境科学, 2013, 32(4): 629-635.

Yang Z J, Cui J, Han S Y, et al. The impact of Arctic ecological security on China's national security and countermeasures [J]. Marine Environmental Science, 2013, 32(4): 629-635.

[7] 邹否否, 密晨曦. 北极渔业及渔业管理之现状及展望 [J]. 太平 洋学报, 2016, 24(3): 85-93.

Zou L L, Mi C X. Status and prospects of Arctic fisheries and fisheries management [J]. Pacific Journal, 2016, 24(3): 85-93. 